\title{
Driver Success in the NASCAR Sprint Cup Series: The Impact of Multi-Car Teams
}

\author{
Craig A. Depken, $\mathrm{II}^{\dagger}$ and Larisa Mackey ${ }^{\dagger \dagger}$
}

November 2009

\begin{abstract}
This paper explores the impact of multi-car teams on driver wins, total points, and total earnings in the NASCAR Sprint Cup Series for the years of 2005 through 2008. Early in NASCAR's history, multi-car teams were rare as the conventional wisdom was that multi-car teams would have poor chemistry which would negatively impact driver performance. Recently, however, multi-car teams have become more popular. Using season-level data, we show that multi-car teams generally enjoy a competitive advantage on the track over single-car teams but that diminishing returns to the number of cars on a team mitigates the motivation for arbitrarily large teams.
\end{abstract}

JEL Classification Codes: D23, L83, L25

Keywords: peer effects, returns to scale, motor sports

${ }^{\dagger}$ Department of Economics, Belk College of Business, UNC-Charlotte, Charlotte, NC 28223, 704-687-7484 (Office), 704-687-6442 (fax), E-mail: cdepken@uncc.edu

${ }^{\dagger}$ Department of Marketing, Belk College of Business, UNC-Charlotte, Charlotte, NC 28223, E-mail: mail: 1macke12@uncc.edu 


\section{Introduction}

Multi-car teams have been a relatively recent development in the National Association of Stock Car Automobile Racing (NASCAR) Sprint Cup Series. While many two car teams existed in the early years of NASCAR's history, driver jealousy tended to reduce team performance suggesting that NASCAR was not a sport in which team-level cooperation was practical. This changed in the late 1980s when Hendrick Motorsports expanded from a one-car to a two-car team that performed better than expected. Since then, the trend toward multi-car teams has been steady but not without controversy. In 2005, 27 of 38 teams (71\%) Sprint Cup Series were single-car teams, but by 2008, only 8 of 24 teams (33\%) were single-car operations. Notwithstanding this trend, in 2005 NASCAR announced a plan to limit the number of cars on each team lest competitive and economic balance be undesirably distorted (Graves, 2005). Similar to other sports, NASCAR officials argued for a league-wide policy concerning the distribution of labor and the concentration of talent because, left to their own desires, team owners would have arbitrarily large teams or would continually pursue more talent.

While these concerns have generally been dispelled in other sports, the concerns and policies in NASCAR seem to have outpaced the existing economic research on the impact of multi-car teams on driver performance. If there are diminishing returns to additional teammates, this would imply an internal solution for the optimal number of cars on a team, thereby potentially mitigating the fears over competitive and economic balance.

This paper seeks to fill this gap by investigating how driver success is influenced by the number of cars on the driver's team. We do so in the context of season-level data for the 114 drivers in the NASCAR Sprint Cup Series for the 2005 through 2008 seasons. To preview our results, we find that driver performance is generally enhanced by additional teammates but at a 
decreasing rate. While there seems to be some evidence that in 2007 and 2008 the competitive balance of NASCAR's elite series was less than it was in 2005, there is not enough information in the current data to identify whether this represents a trend.

\section{Multi-Car Teams in NASCAR}

There are many factors that influence the outcome of a NASCAR Sprint Cup Series race. While

the sport is organized to highlight driver talent and skill, primarily through standardizing the cars, the ability of the driver's crew chief to put together a creative race-day strategy, the speed and skill of the pit crew, and "luck" also play large roles in driver success. One unanswered question is to what extent the number of cars on a driver's team influences driver success.

There are many possible rationales for fielding a multi-car operation in NASCAR, including taking advantage of economies of scale and scope in order to reduce the costs associated with research and production of the race cars. As there are considerable fixed costs for operating a NASCAR team, the incremental cost to a team associated with an additional car is relatively low. In terms of development, a multi-car team can utilize mechanics, fabricators, and other shop personnel across multiple teams thereby saving on labor costs. Before the economic slowdown in 2008, NASCAR allocated test slots at various tracks around the country to each car rather than to each team. Thus, multi-car teams were granted more testing opportunities the data generated from which, if shared across the multiple cars, would represent another source of cost reductions.

However, as shown by Pfitzner \& Richel (2005), multi-car teams can also experience an increase in revenues. One way this can occur is through knowledge sharing leading up to and during the race. While testing is generally aimed at gleaning general information about engines, drive-trains, and aerodynamics, qualifying and practice sessions leading up to a race provide 
valuable information for drivers and crew chiefs about the condition of the track, the wear of tires, and how the car should be configured for optimal performance that weekend. Team-work during qualifying might be important because there are only a limited number of available atlarge qualifying slots available for each of the thirty-six NASCAR Sprint Cup races. If one or more cars on a team are vying for an at-large qualifying slot, information sharing might prove the difference in qualifying and vying for a share of the race purse. Other cars not vying for an at-large qualifying slot might be able to take advantage of knowledge sharing on a multi-car team to improve their starting and finishing positions, thereby increasing their portion of the race purse.

Another advantage a multi-car team might have over a single-car operation is in the area of race-time cooperation. During the race, teammates might cooperate in terms of drafting or blocking which can improve the finishing position of one or more of the drivers. Multi-car teams might be able to leverage their single-race cooperation to improve the standing of one or more drivers in the season-level contest for the Sprint Cup championship which is determined by the "Chase for the Cup," in which the top twelve drivers compete for the championship during the last ten races of the season. These race-day and season-end advantages might translate to yet another advantage for a multi-car team: longer and more lucrative sponsorships.

\section{Data and Empirical Methodology}

To test the extent that multi-car teams influence driver success, we evaluate season-level data describing 114 drivers over four NASCAR Sprint Cup seasons from 2005-2008. The data were obtained from NASCAR and describe the number of starts, the number of pole positions won, the number of wins, the number of performance points, and the earnings of each driver that qualified for at least one race during the season. We also identify the owner of each car and 
determine the number of cars per team, and whether the driver qualified for the "Chase for the Cup,” and whether the driver was in his rookie season.

Our general estimating equation is:

$$
\begin{aligned}
& \text { DEP }_{i t}=\beta_{0}+\beta_{1} \text { TEAMCARS }_{i t}+\beta_{2} \text { TEAMCARSSQ }_{i t}+\beta_{3} \text { STARTS }_{i t}+\beta_{4} \text { POLES }_{i t}+ \\
& \beta_{5} \text { ROOKIE }_{i t}+\beta_{6} \text { MADECHASE }_{i t}+\gamma \text { YEAR }_{t}+\varepsilon_{i t},
\end{aligned}
$$

where $D E P_{i t}$ is, alternatively, total wins, total performance points, and total real race winnings of the driver, the $\beta$ 's and $\gamma^{\prime}$ s are parameters to be estimated, $\varepsilon_{\text {it }}$ is a composite error term which allows for driver specific effects, $i=1 \ldots 114$ and $t=2005 . .2008$. The dependent variables are proxies for three of the possible benefits to multi-car teams enumerated in the previous section.

The first is the season-end number of race victories for each driver (WINS). This dependent variable reflects race-level performance. The second dependent variable is driver performance points (POINTS), which reflects season-long performance. ${ }^{1}$ The third dependent variable is season-end race earnings (RWINNINGS), which captures season-long on-the-track success measured in dollars. The dollars won by the driver is highly correlated with performance points but can be substantially influenced by better driver performance in races with greater purses, e.g., the Daytona 500.

As the number of wins is a discrete variable, we apply Poisson and Negative Binomial estimators to the models with WINS as the dependent variable. The number of performance points and the level of earnings by the drivers are both quasi-continuous so we use linear panel estimators in these two cases.

\footnotetext{
${ }^{1}$ Performance points are awarded at the end of each race according to finishing position. The winner received 185 points with positions two through six receiving five points fewer for each place; positions seven through eleven receive three points fewer for each place; positions twelve through forty three receive three points less for each position. Thus, a second place finish yields 180 points and a forty-third place finish receives thirty four points. There are also ten bonus points available for each race: five points for leading a single lap and five points for leading the most laps.
} 
The explanatory variables include the number of cars on each driver's team (TEAMCARS) and its quadratic (TEAMCARSSQ). If there are no peer effects for multiple car teams then we would expect the parameters on the linear and the quadratic terms to be insignificant. However, if multiple cars on a team generate positive (negative) peer effects for the average driver, then we expect the parameter on the linear term to be positive (negative). If there are diminishing returns to the number of cars, then we expect a negative parameter on the quadratic term; if there are constant returns, then we expect to see an insignificant parameter on the quadratic term; and if there are increasing returns to having multiple cars then we expect to see a positive parameter on the quadratic term.

We also control for the number of races the driver started during the season (STARTS). Only the top thirty-five cars in owner-points the week of a race are guaranteed a starting position in the race, thus not every car is guaranteed to qualify for each race. ${ }^{2}$ The remaining eight spots are allocated to the eight fastest non-guaranteed qualifiers, unless a non-guaranteed previous NASCAR Sprint Cup champion wishes to participate in the race, in which case only seven nonguaranteed qualifiers start the race. The number of starts is expected to be positively related to each of the dependent variables as without starting the race there is no chance of winning the race, and no performance points and no money will be earned.

We also control for the number of pole positions each driver earned during the season (POLES). Winning the pole position is positively correlated with winning the race (see Depken

\footnotetext{
${ }^{2}$ Owner points are awarded in the same manner as driver points. The primary difference is that the driver does not receive points unless he starts the race whereas the owner receives points regardless of which driver starts the race. Furthermore, owners receive points for attempting to qualify for the race whereas drivers do not receive points unless they do qualify for the race.
} 
and Zhang, 2009) but more generally improves the finishing position of the driver which corresponds with greater performance points and greater earnings. ${ }^{3}$

We also control for whether the driver is a rookie, that is, the driver is in their first year of racing at the NASCAR Sprint Cup level (ROOKIE). New drivers might take time to acclimate to the higher speeds, and different cars and strategies involved with racing at the highest level. During their transition from the lower level of NASCAR racing the rookie driver might not earn as many performance points and might not earn as much money as a "veteran” driver.

We also control for whether a driver qualified for the "Chase for the Cup" (MADECHASE). NASCAR introduced a playoff system in 2004 in which a select number of drivers, currently twelve, are identified as having qualified for an opportunity to win the overall championship. After the first twenty-six races, the top twelve drivers have their points totals reset to 5,000 and are then awarded 10 points for each victory during the first twenty-six races. For the last ten races, points are awarded according to the standard NASCAR formula. At the end of the ten "chase" races the driver with the most performance points is awarded the Sprint Cup Championship. ${ }^{4}$ Because of the adjustment to the total points earned by those in the chase, we include a dummy variable that takes a value of one if a driver qualified for the cup and zero otherwise. It is anticipated MADECHASE will have a positive relationship with all three dependent variables.

Our final independent variables are three dummy variables for the years 2006, 2007, and 2008. These dummy variables control for season-specific impacts on the odds of winning a race,

\footnotetext{
${ }^{3}$ The pole winner also receives a monetary bonus and is granted first choice of pit stalls. Pit stall selection is allocated according to qualifying finish, unless qualifying is suspended or does not occur in which case pit stall selection is allocated according to owners points. At many tracks, certain pit stalls are thought to provide strategic advantages.

${ }^{4}$ A parallel "chase" for the owner's cup is also created in which the twelve owners with the most owner points after twenty-six races have their owner points reset to 5,000. The owner with the most points at the end of the last ten races wins the Sprint Cup Series owner's title.
} 
of the level of performance points earned, or the amount of money won for all drivers in the circuit. Furthermore, during the 2007 season NASCAR introduced the so-called "Car of Tomorrow” at select Sprint Cup races and for all races in the 2008 season. The year dummy variables help control for any influence the Car of Tomorrow had on the overall competitiveness of NASCAR.

The descriptive statistics of the data are presented in Table 1 . As can be seen, the average number of wins per driver during the sample period is rather small. In fact there were only 24 drivers who won at least one race during these four NASCAR seasons and only 9 that won more than three in a single season during the period. The average driver earned 2,290 performance points during the season. The variation in performance points is high during the sample period with the minimum number of points earned being 0 (two drivers earned zero points in one start each: Stephen Leicht in 2007 and Johnny Sauter in 2006), and the maximum number of points earned being 6,723 by Jimmie Johnson in 2007. The average season-end winnings, measured in 2004 dollars, was $\$ 2.135$ million with considerable variation, the lowest earnings being $\$ 49,080$ (Brian Simo in 2006) and the greatest earnings being \$7.609m (Jimmie Johnson in 2006). ${ }^{5}$ The average number of cars per team during the sample period was 2.5, with the minimum being one and the maximum being five. ${ }^{6}$ The average number of pole positions won during the sample period was 0.425 per driver and the average number of starts was 20.5 out of a possible thirty six races per season. Of the sample observations approximately seven percent

\footnotetext{
${ }^{5}$ The season-end earnings used in this study include only earnings derived from race purses and do not include season-end bonuses. While teams and drivers earn considerable revenues off the track from endorsements, sponsorships, memorabilia, and appearance fees, these additional revenues are generally not reported by NASCAR teams. We therefore focus only on the dollars earned on the track.

${ }^{6}$ We consider formal teams, that is multiple cars with the same owner, and not so-called "affiliated" teams. Affiliated teams, such as Roush Fenway-Yates, or Gibbs-Hall of Fame, are referred to as "vendor relationships" by NASCAR because the affiliations generally share inputs such as engines, transmissions, or chassis. Such relationships seem directed more toward cost savings rather than on-track cooperation and therefore have different incentives than formal teams.
} 
were rookie drivers, and approximately $15 \%$ of observations corresponded with drivers who qualified for the season-ending "Chase for the Cup." The distribution of observations across the four seasons in the sample is interesting: approximately $27.91 \%$ of the observations coming from the 2005 season, $25.58 \%$ from the 2006 season, $22.92 \%$ from the 2007 season, and $23.58 \%$ from the 2008 season. $^{7}$ The trend suggests that there were more drivers in the first two years of the sample and the number of drivers settled at a lower level during the last two years of the sample. This would have been caused, for example, by fewer retirements, fewer injuries, or by fewer new teams.

\section{Empirical Results and Discussion}

The estimation results are presented in Table 2. Generally, the results support intuition concerning the impact of being a rookie, of having more starts, more pole positions, and of making the "chase." Furthermore, the impact of the number of cars on a team is consistently positive in the level and negative in the quadratic, suggesting that there are diminishing returns to the number of cars on the team.

Taking the three dependent variables in turn, the first two models in Table 2 use the number of wins as the dependent variable. As WINS is a discrete variable, we first apply a Poisson estimator to the data. The results are consistent with intuition. The more cars on a driver's team the more wins a driver will have at the end of the season, but the benefits to additional cars are diminishing. The other variables carry the expected signs and significance. The Poisson regression results are not directly interpretable, although the signs of the parameters indicate whether the variable generally contributes to more or fewer wins during the course of a driver's season. We estimate the marginal impacts of each variable on the level of WINS for the sub-sample of observations that had at least on race victory during the sample period. The

\footnotetext{
${ }^{7}$ Percentages don't sum exactly to one because of rounding errors.
} 
marginal impact of an additional car on the number of wins is 0.553 , evaluated at a sub-sample mean of 3.5 cars, each pole won increased the number of victories by 0.216 , evaluated at a subsample mean of 1.52 pole positions won, and each additional start increased the number of wins by 0.44 , evaluated at the sub-sample mean of 36 starts. Those drivers who made it to the "Chase for the Cup" had an average of 1.75 more victories, ceteris paribus. ${ }^{8}$ The results using the negative binomial estimator are reported in Table 2 for completeness, although the overall test for goodness of fit in the Poisson model does not suggest there is a problem of over dispersion, which would otherwise invalidate the Poisson estimator. The marginal effects of the negative binomial estimation are almost identical as those for the Poisson estimator.

The second two models in Table 2 use season-end performance points as the dependent variable. In this case we estimate both the random effects and the more conservative fixed effects models, recognizing that there is considerable unobserved driver and team heterogeneity in the data. Given the large number of drivers $(\mathrm{N}=114)$ and small time dimension $(\mathrm{T}=4)$, the random effects model might be more efficient. However, if there is considerable unobserved driver and team heterogeneity that is correlated with one or more of the independent variables, for example if the quality of the crew chief is correlated with the number of pole positions the driver earns (which is likely to be the case), then the fixed effects model might prove superior even as it sacrifices more degrees of freedom.

From the second two models, it is clear that the random effects model is superior to pooled OLS given the Breusch-Pagan test for no driver effects. However, in the random effects model neither the number of cars nor its quadratic is statistically significant, and the parameter on the quadratic term takes the "wrong" sign. The rest of the variables have statistically significant parameters that take the expected sign except for the dummy variable for year 2006.

\footnotetext{
${ }^{8}$ These results are available from the authors upon request.
} 
The fixed effects model using performance points as the dependent variable is superior to the random effects according to the Hausman test. The fixed effects are jointly different from zero, as indicated by the significant F-test statistic. The individual parameter estimates take the expected signs, although the parameter on the quadratic of team cars is insignificant at conventional levels. However, the joint test that the parameters on TEAMCARS and TEAMCARSSQ are both equal to zero is rejected $(\mathrm{F}=2.93, \mathrm{p}=0.059)$ as is the non-linear combination of these parameters which provides a point estimate for the optimal number of cars to maximize performance points $(\mathrm{t}=5.24, \mathrm{p}=0.00)$. The results suggest that each pole position won is worth an additional 61 performance points, which is a combination of higher finishing position and increased odds of earning five or ten bonus points during a race. Each start is worth an average of 94 performance points, and rookies tend to earn approximately 150 fewer performance points than their veteran counterparts, all else equal. Finally, by construction, there is a considerable break between the performance points of those in the "Chase for the Cup" and those not. The year dummy variables indicate that over the sample period the average driver earned fewer performance points later in the sample than earlier, suggesting that the competitive balance of the NASCAR Sprint Cup Series was declining over the sample period.

The final two models in Table 2 use season-level race winnings (converted to 2000 dollars using the annualized consumer price index) as the dependent variable. Here, as was the case with the performance-points models, the random effects model is superior to pooled OLS, but the fixed effects model is superior to the random effects model, notwithstanding the degrees of freedom sacrificed in the fixed effects model. The results suggest that the average driver's season-end earnings are greater with more cars on his team but that there are diminishing returns to these increases. Unlike in the case of performance points, there is no significant relationship 
between total winnings and either the number of poles won or being a rookie, after controlling for unobserved driver heterogeneity. There is a positive and significant relationship between total winnings and both the number of starts and whether the driver qualified for the "chase." Consistent with the models using performance points, the average earnings per driver have been falling during the sample period, which might be contributing to the incentives for single-car teams to merge with other teams.

We can use the estimation results from the performance-points models and the real winnings model to calculate a "back of the envelope" value of the optimal number of cars for a team from the point of view of maximizing performance points and real winnings. From the functional form estimated, the dependent variable will be maximized when the following condition is met: $\mathrm{N}^{*}=-\beta_{1} /\left(2 \beta_{2}\right)$, where $\beta_{1}$ and $\beta_{2}$ are the appropriate parameters on NUMCARS and NUMCARS2, respectively.

Using the results from the fixed effects model of performance points, the estimates suggest that performance points are maximized when the number of cars is approximately 3.36, which is statistically different from one [95\% confidence interval: 2.16-4.57]. Given the integer problem, the optimal team size would be between two and four cars. Thus, performance points are estimated to be maximized when a driver has two teammates on the track. Using the results from the fixed effects model of total real winnings, the estimates suggest that real winnings are maximized when the number of cars is approximately 2.35 which is statistically different from one [95\% confidence interval: 1.95-2.74]. While the confidence interval is a bit tighter with respect to the optimal number of cars on a team to maximize earnings, the two sets of models point to an optimal number of cars on a team being between two and three. Indeed, of the twenty 
four teams that fielded cars during the 2008 season, twelve (50\%) were either two car or three car teams, nine were single car teams, two teams had four cars each, and one team had five cars.

\section{Conclusions}

This paper investigates whether driver success in NASCAR's elite racing series, the Sprint Cup Series is influenced by the number of other drivers on his team. The trend in NASCAR's Sprint Cup has been toward multi-car teams. There are arguments on both the cost and benefit side of having multiple cars on a NASCAR team. On the cost side there are potential cost reductions through economies of scale and scope. On the benefit side there are pre-race benefits through information sharing, single-race benefits through teammate cooperation which leads to higher finishing positions and possibly more race victories, and season-long benefits from cooperation as reflected in performance points and race winnings.

However, there are fears that multi-car teams might come to dominate the sport at the expense of competitive balance and the financial viability of teams with fewer cars. In response, NASCAR has discussed the prospect of placing an arbitrary limit on the number of cars a particular team can operate. This assumes that there is no diminishing returns to the number of cars on a team, an assumption that has not been tested to date.

Using data describing 114 drivers from the 2005-2008 NASCAR Sprint Cup seasons, we

find that drivers on multi-car teams tend to win more victories, controlling for the number of pole positions won, the number of races started by the driver, whether the driver was a rookie, and whether the driver qualified for the playoffs in NASCAR, known as the "Chase for the Cup." The evidence suggests that there are benefits to having multiple drivers on a team, regardless of how driver success is measured, but that the benefits decrease with the number of cars on a team. 
An interesting result was that in both performance points and in season earnings, the average driver earned less in both measures in the 2007 and 2008 seasons relative to the 2005 season, suggesting that NASCAR has become less competitively balanced during this period. Whether this has to do with the proliferation of multi-car teams or whether it has to do with other factors, such as the Car of Tomorrow adopted during the 2007 season, is a matter for further research.

While this study has not addressed the cost-side motivations for multi-car teams, the results herein suggest there are significant revenue-side motivations for the trend toward multicar teams. However, for both performance points and season winnings there are diminishing returns to the number of teammates on driver performance, suggesting an interior solution for the optimal number of cars on a team to be between two and three. Thus, while the trend toward multi-car teams in NASCAR's elite circuit might be a cause of concern to some, the data seem consistent with other areas of sports in which diminishing returns reduce the incentive to have arbitrarily large teams. 


\section{References}

Depken, Craig and Ying Zhang (2009). “The Value of the Pole: Evidence from NASCAR,” mimeo, Department of Economics, The Belk College of Business, UNC Charlotte.

Graves, Gary (2005). “NASCAR Plans to Limit Multicar Teams,” USA TODAY, October 8, 2005,

retrieved from www.usatoday.com on March 15, 2008.

National Association for Stock Car Auto Racing. (2008, March). 2005-2008 Standings Data Obtained from the National Association for Stock Car Auto Racing.

Pfitzner, C. \& Rishel, T.D. (2005). Do Reliable Predictors Exist for the Outcomes of NASCAR Races? The Sport Journal, Volume 8, Number 2, Article 1543-9518. 
Table 1: Descriptive Statistics of the Data

\begin{tabular}{|l|l|l|l|l|}
\hline Variable & Mean & Std. Deviation & Minimum & Maximum \\
\hline WINS & 0.481 & 1.401 & 0 & 10 \\
\hline POINTS & $2,290.29$ & $2,170.43$ & 0 & 6,723 \\
\hline WINNINGS & $2,135,425$ & $1,875,449$ & $49,080.82$ & $7,609,953$ \\
\hline TEAM CARS & 2.51 & 1.287 & 1 & 5 \\
\hline TEAMCARS & 7.993 & 7.146 & 1 & 25 \\
\hline POLES & 0.425 & 1.109 & 0 & 8 \\
\hline STARTS & 20.538 & 15.192 & 0 & 36 \\
\hline ROOKIE & 0.073 & 0.261 & 0 & 1 \\
\hline MADECHASE & 0.146 & 0.353 & 0 & 1 \\
\hline YEAR 2005 & 0.266 & 0.442 & 0 & 1 \\
\hline YEAR 2006 & 0.255 & 0.437 & 0 & 1 \\
\hline YEAR 2007 & 0.229 & 0.421 & 0 & 1 \\
\hline YEAR 2008 & 0.235 & 0.425 & 0 & 1 \\
\hline $\begin{array}{l}\text { Notes: Data comprise an unbalanced panel of 301 observations for 114 drivers. } \\
\text { reference year in the regression models presented in Table 2. }\end{array}$ \\
\hline
\end{tabular}


Table 2: Estimation Results

\begin{tabular}{|c|c|c|c|c|c|c|}
\hline & Poisson & Neg. Binomial & Random Effects & Fixed Effects & Random Effects & Fixed Effects \\
\hline & WINS & WINS & POINTS & POINTS & RWINNINGS & RWINNINGS \\
\hline \multirow[t]{2}{*}{ TEAMCARS } & $2.282 * * *$ & $2.496 * * *$ & 38.876 & $144.647 * *$ & $222,510.418 *$ & $357,401.916 * *$ \\
\hline & $(2.65)$ & $(2.90)$ & $(0.68)$ & $(2.20)$ & (1.91) & $(2.55)$ \\
\hline \multirow[t]{2}{*}{ TEAMCARS $^{2}$} & $-0.270 * *$ & $-0.298 * *$ & 13.607 & $-21.899 *$ & $-23,667.634$ & $-77,339.828 * *$ \\
\hline & $(-2.20)$ & $(-2.41)$ & $(1.24)$ & $(-1.74)$ & $(-1.07)$ & $(-2.53)$ \\
\hline \multirow[t]{2}{*}{ POLES } & $0.156 * * *$ & $0.197 * * *$ & $84.997 * * *$ & $61.120 * * *$ & $135,718.910^{* * *}$ & $-24,794.646$ \\
\hline & (3.18) & (3.15) & $(4.78)$ & (3.91) & (3.47) & $(-0.81)$ \\
\hline \multirow[t]{2}{*}{ STARTS } & $0.318^{* *}$ & $0.360^{* *}$ & $94.614^{* * *}$ & $94.440^{* * *}$ & $96,012.555^{* * *}$ & $89,634.271^{* * *}$ \\
\hline & (2.35) & $(2.54)$ & $(75.5)$ & (41.3) & $(47.0)$ & (31.7) \\
\hline \multirow[t]{2}{*}{ ROOKIE } & -0.142 & -0.119 & $-178.674 * * *$ & $-147.749 * *$ & $-250,399.483^{* *}$ & $-2,664.254$ \\
\hline & $(-0.33)$ & $(-0.24)$ & $(-2.88)$ & $(-2.17)$ & $(-2.22)$ & $(-0.027)$ \\
\hline \multirow[t]{2}{*}{ MADECHASE } & $1.520 * * *$ & $1.530 * * *$ & $2,709.893 * * *$ & $2,359.956 * * *$ & 1164674.791*** & $527,725.845^{* * *}$ \\
\hline & $(4.65)$ & $(4.98)$ & (53.8) & $(28.8)$ & $(7.42)$ & (3.63) \\
\hline \multirow[t]{2}{*}{ YEAR06 } & -0.058 & -0.127 & -42.750 & -38.266 & $-52,722.866$ & $-55,603.793$ \\
\hline & $(-0.17)$ & $(-0.32)$ & $(-1.00)$ & $(-0.97)$ & $(-0.61)$ & $(-0.84)$ \\
\hline \multirow[t]{2}{*}{ YEAR07 } & -0.177 & -0.366 & $-93.224 * *$ & $-84.306^{*}$ & $-168,905.288^{* *}$ & $-165,152.009 * *$ \\
\hline & $(-0.57)$ & $(-1.24)$ & $(-2.37)$ & $(-1.89)$ & $(-2.00)$ & $(-2.43)$ \\
\hline \multirow[t]{2}{*}{ YEAR08 } & -0.109 & -0.228 & $-113.613^{* * *}$ & $-80.477^{*}$ & $-215,713.285^{* * *}$ & $-175,616.693^{* *}$ \\
\hline & $(-0.28)$ & $(-0.62)$ & $(-2.69)$ & $(-1.81)$ & $(-2.62)$ & $(-2.02)$ \\
\hline \multirow[t]{2}{*}{ Constant } & $-16.828 * * *$ & $-18.681 * * *$ & $-218.624 * * *$ & -150.287 & $-315,536.475^{* * *}$ & $37,137.936$ \\
\hline & $(-3.40)$ & $(-3.54)$ & $(-3.34)$ & $(-1.58)$ & $(-2.68)$ & $(0.28)$ \\
\hline Specification Test $\mathrm{t}^{\mathrm{a}}$ & 170.39 & & $6.85^{* * *}$ & $86.30 * * *$ & $22.84 * * *$ & $154.85 * * *$ \\
\hline $\mathrm{H}_{0}$ : No Fixed Effects & & & & $1.95^{* * *}$ & & $2.68^{* * *}$ \\
\hline Observations & 301 & 301 & 301 & 301 & 301 & 301 \\
\hline No. of drivers & & & 114 & 114 & 114 & 114 \\
\hline $\begin{array}{l}\text { Notes: Dependent var } \\
\text { and the Negative Bino } \\
\text { Effects models is a Br } \\
\text { the null being the Ran } \\
\text { consistent and the Rar }\end{array}$ & $\begin{array}{l}\text { listed in s } \\
\text { is a test o } \\
\text { 1-Pagan te } \\
\text { Effects es } \\
\text { Effects es }\end{array}$ & sten & $\begin{array}{l}\text { variables as de } \\
\text { ted Robust } \mathrm{z} \text { st } \\
\text {, the specifica } \\
\text { efficient again } \\
* * \mathrm{p}<0.01 \text {, ** }\end{array}$ & $\begin{array}{l}\text { in Table } 1{ }^{\mathrm{a}} \\
\text { s in parenth } \\
\text { est for the Fi } \\
\text { alternative t } \\
5,{ }^{*} \mathrm{p}<0.1\end{array}$ & $\begin{array}{l}\text { specification tes } \\
\text { the specificatio } \\
\text { Effects models i } \\
\text { he Fixed Effects }\end{array}$ & $\begin{array}{l}\text { ween the Poisson } \\
\text { t for the Random } \\
\text { Iausman test with } \\
\text { nator is }\end{array}$ \\
\hline
\end{tabular}

